\title{
Estudo bibliográfico das tecnologias utilizadas no tratamento do esgoto e a legislação em vigor no Brasil
}

O ser humano, em seu cotidiano, produz uma série de resíduos, podendo ser eles em esfera residencial, comercial, industrial e agrícola. Esses resíduos nem sempre têm um tratamento correto, e consequentemente, são depositados na natureza, contaminando nosso bem mais precioso: a água. No entanto, nos últimos anos, expandiram novas tecnologias de tratamento, e também as legislações específicas para o saneamento básico no país. 0 presente estudo é uma pesquisa bibliográfica desenvolvida a partir de um levantamento em artigos, periódicos e sites. Conclui-se que o mercado disponibiliza de vários tratamentos tecnológicos para o esgoto, e que a cada dia há uma lenta evolução na cobertura desse serviço à população brasileira, por meio da aplicabilidade da Lei de Saneamento Básico e Plano Nacional de Saneamento Básico.

Palavras-chave: Esgoto; Tratamento; Tecnologia; Legislação.

\section{Bibliographic study of the technologies used in sewage treatment and the legislation in force in Brazil}

Human beings, in their daily lives, produce a series of residues, which can be residential, commercial, industrial and agricultural. These wastes are not always properly treated, and consequently, they are deposited in nature, contaminating our most precious possession: water. However, in recent years, new treatment technologies have expanded, as well as specific sanitation legislation in the country. This study is a bibliographic research developed from a survey in articles, journals and websites. It is concluded that the market offers various technological treatments for sewage, and that there is a slow evolution in the coverage of this service to the Brazilian population, through the applicability of the Basic Sanitation Law and the National Basic Sanitation Plan.

Keywords: Sewer; Treatment; Technology; Legislation.

Topic: Engenharia Sanitária

Reviewed anonymously in the process of blind peer.
Received: 11/01/2019

Approved: $12 / 02 / 2019$
Everton Narciso de Oliveira

Pontifícia Universidade Católica de Goiás, Brasil

http://lattes.cnpq.br/3113010310497777

eno.professor@gmail.com

\section{Mariana de Freitas Ferreira}

Centro Universitário de Goiatuba, Brasil

http://lattes.cnpq.br/2771885420228426

mafreits@gmail.com

Walison Feitosa de Oliveira

Centro Universitário de Goiatuba, Brasil

http://lattes.cnpq.br/9366430527909061

walisonvieira48@gmail.com
Rodrigo Rodrigues de Oliveira

Faculdade de Filosofia e Ciências Humanas de Goiatuba, Brasil

http://lattes.cnpq.br/1576539375792821

rodrigorodrigues1306@gmail.com
Referencing this:

OLIVEIRA, E. N.; FERREIRA, M. F.; OLIVEIRA, W. F.; OLIVEIRA, R. R. Estudo bibliográfico das tecnologias utilizadas no tratamento do esgoto e a legislação em vigor no Brasil. Natural Resources, v.9, n.1, p.20-27, 2019. DOI: http://doi.org/10.6008/CBPC22379290.2019.001.0003 


\section{INTRODUÇÃO}

O crescimento acelerado da população mundial, juntamente com o crescente volume de esgotos sanitários produzidos, e ao mesmo tempo sendo despejados nos recursos hídricos e no solo, com pouco ou nenhum tipo de tratamento, vem contribuindo para a degradação do meio ambiente, através da poluição dos recursos naturais, desestabilização dos ecossistemas e causando graves problemas ambientais e sociais. Nesse sentido a busca crescente por soluções de saneamento ambiental e tecnologias de tratamento de esgotos é parte fundamental do processo de recuperação e manutenção da qualidade de vida da população e do meio ambiente (SCOTTÁ, 2015).

A coleta de esgoto é um serviço pouco praticado na maior parte do território brasileiro. O tratamento é algo ainda mais incomum, originando graves consequências ao meio ambiente e à saúde pública. No Centro-Oeste do país, a segunda com menor percentual de municípios com coleta de esgoto as situações mais críticas estão nos estados de Mato Grosso e Goiás. Em Mato Grosso, 81\% dos municípios não têm rede de coleta de esgoto e em Goiás essa taxa é de 72\%. Em Mato Grosso do Sul 44\% dos municípios faz tratamento, já no Distrito Federal apresenta-se situação acima da média nacional (RODRIGUES, 2011).

Além de vários problemas socioambientais, o lançamento de efluentes nos recursos hídricos resulta em grandes impactos na vida aquática e o meio ambiente como um todo. Assim, não existe um sistema de tratamento padrão para ser utilizado, pois vários fatores irão influenciar na escolha das opções tecnológicas, tais como, disponibilidade de área, qualidade desejada para o efluente tratado, da legislação referente ao local, entre outros (PIMENTA et al., 2002).

Pimenta et al. (2002) ressalta ainda que o investimento no tratamento de efluentes, pode significar um grande salto para o desenvolvimento em termos da dotação da infraestrutura requerida para proteger o meio ambiente e melhorar a qualidade de vida da população, assim como propiciar novas oportunidades de negócios. Assim, a coleta, o tratamento e a disposição ambientalmente adequada de efluentes são fundamentais para a melhoria do quadro de saúde da população e pré-requisito para busca da sustentabilidade.

\section{METODOLOGIA}

Este estudo é uma revisão bibliográfica desenvolvida a partir de um levantamento em artigos científicos, periódicos e sites referente a tecnologias utilizadas no tratamento de esgoto e a legislação em vigor no país, já que hoje assuntos relacionados à preservação do meio ambiente estão cada vez mais ganhando destaque na área cientifica.

\section{DISCUSSÃO TEÓRICA}

A Pesquisa Nacional De Saneamento Básico (PNSB) pode ser realizada por meio de entrevistas pessoais com questionários em papel junto aos órgãos públicos e às entidades privadas que constam no cadastro de prestadores de serviços de saneamento básico (prefeituras, companhias estaduais ou municipais 
de saneamento básico, fundações, consórcios intermunicipais, empresas privadas de saneamento básico e associações comunitárias).

Em 1974, iniciou-se o primeiro levantamento sobre saneamento básico no Brasil. Em 1977, a segunda edição entrou em vigor. Em 1989 a terceira edição da pesquisa foi reformulada. No ano de 2000, a quarta edição da pesquisa foi reformulada e ficou mais abrangente. Em 2008, a quinta edição foi lançada novamente reformulada e mais ampla (DUTRA, 2018).

Segundo Mota (1997), os esgotos são compostos por constituintes físicos, químicos e biológicos. Não havendo despejos industriais a composição do esgoto doméstico ou sanitário é razoavelmente constante. Este efluente contém aproximadamente $99,9 \%$ de água, e apenas $0,1 \%$ de sólidos. Já os esgotos industriais além da matéria orgânica, podem carrear substâncias químicas tóxicas ao homem e outros animais. 0 tratamento de esgoto consiste na estabilização da matéria orgânica de um certo efluente. Assim, o tratamento busca transforma a matéria orgânica em inorgânica (mineralização e consequente redução de DBO) e a remoção de microrganismos patogênicos (PIMENTA et al., 2002).

\section{Etapas de tratamento do esgoto}

O esgoto, após a coleta e o transporte, deve ser direcionado para o tratamento, onde se objetiva que este adquira características que permitam o seu lançamento em corpos hídricos, atendendo aos padrões de lançamento de efluente, vigentes nas legislações. As diferentes fases possuem as funções de remover os sólidos grosseiros, os sólidos suspensos, a matéria orgânica dissolvida, os nutrientes e os agentes patogênicos, através de processos físicos, físico-químicos e biológicos (OLIVEIRA, 2014).

Através das técnicas de tratamento é possível remover os poluentes dos esgotos, os quais viriam a causar uma deterioração da qualidade da água e a possibilidade de transmissão de doenças. $O$ tratamento preliminar deve estar presente em todas as estações de tratamento de esgotos. Já as unidades do tratamento primário podem ou não estar presentes no fluxograma das estações. A remoção dos sólidos grosseiros é feita por meio de grades, que podem ser grossas, médias e finas, dependendo do espaçamento entre as barras. A limpeza das grades pode ser realizada de forma manual ou mecanizada. Já a remoção da areia contida nos esgotos é feita através de caixas de areia manuais ou mecanizados. O mecanismo de remoção da areia é o de sedimentação: a areia, devido às suas maiores dimensões e densidade, vai para o fundo do tanque (BRASIL, 2008).

Brasil (2008) descreve que, no tratamento primário os esgotos fluem vagarosamente, permitindo que os sólidos em suspensão, por possuírem uma densidade maior que a do líquido, sedimentem-se gradualmente no fundo. Os óleos e graxas, por possuírem uma densidade menor que do líquido, sobem para a superfície dos decantadores, onde são coletados e removidos para posterior tratamento.

No tratamento secundário, ocorre a remoção de Demanda Bioquímica de Oxigênio (DBO) em suspensão, DBO solúvel e nutrientes. Tem o objetivo de acelerar mecanismos de degradação que ocorrem naturalmente nos corpos receptores. Nesta etapa, ocorre a inclusão de uma etapa biológica, onde a remoção da matéria orgânica é efetuada por reações bioquímicas, realizadas por microrganismos. Já no tratamento 
terciário ocorre a remoção de poluentes específicos e também aqueles poluentes (nutrientes, patogênicos, compostos não biodegradáveis, metais pesados, sólidos inorgânicos dissolvidos e sólidos em suspensão remanescentes) que não foram removidos no tratamento secundário (OLIVEIRA, 2014).

\section{Tecnologias utilizadas no tratamento}

Na década de 1990, Vieira (1996) já descrevia que os resíduos devem ser vistos como um recurso natural a ser conservado e reutilizado, pois esgotos são fonte rica em nitrogênio e em nitrogênio. $O$ esgoto produz matéria orgânica que quando se degrada anaerobiamente produz energia em forma de metano. Outros subprodutos do tratamento de esgoto são o lodo e o efluente, que são utilizados na agricultura.

Para Florencio et al. (2006), as tecnologias de tratamento de esgotos são desenvolvidas tendo por principal referência o lançamento em corpos da água. As exigências para atender aos padrões de qualidade dos corpos receptores e mananciais de abastecimento são restritivas, em decorrência da fragilidade dos ecossistemas aquáticos e da necessidade de preservação dos usos múltiplos da água. Assim, necessita-se de substancial redução da carga de matéria orgânica biodegradável e de sólidos em suspensão, de macronutrientes como o nitrogênio e o fósforo, de remoção ou inativação de diversos grupos de organismos patogênicos, além do controle das concentrações de inúmeros constituintes químicos com propriedades tóxicas à saúde humana e à biota aquática.

A tendência mais inovadora são as estações de tratamento de esgoto construídas em edifícios de vários andares, praticamente sem emissões de ruídos, gases, odores, com menor produção de resíduos sólidos. Já as tecnologias utilizadas no tratamento de esgoto foram evoluindo ao longo dos anos, e hoje tem muitas opções como por exemplo: filtros biológicos, lagoas anaeróbicas e aeróbicas, lodos ativados e suas variações, tratamento anaeróbio (UASB) seguida de lodos ativados, lodo ativado com remoção de nitrogênio e fósforo, tratamento por membranas (MBR) (FOLGOSI, 2014). Para melhor exemplificar três métodos de tratamento de esgoto, selecionaram-se o tratamento biológico, lagoa anaeróbica e o lodo ativado.

Segundo o SAAE (2006), o tratamento biológico é a forma mais eficiente de remoção da matéria orgânica dos esgotos. $\mathrm{O}$ próprio esgoto contém grande variedade de bactérias e protozoários para compor as culturas microbiais mistas que processam os poluentes orgânicos. $\mathrm{O}$ uso desse processo requer o controle da vazão, a recirculação dos microrganismos decantados, o fornecimento de oxigênio e outros fatores. Os fatores que mais afetam o crescimento das culturas são a temperatura, a disponibilidade de nutrientes, o fornecimento de oxigênio, o pH, a presença de elementos tóxicos e a insolação.

O tratamento de lagoa anaeróbica também conhecido como sistema australiano tem como característica a existência de duas lagoas que apresentam sistemas biológicos de tratamento distintos. $\mathrm{Na}$ primeira lagoa de menor dimensão, predomina o sistema anaeróbio, fazendo assim um tratamento parcial que alivia sobremaneira o tratamento da segunda lagoa que é uma lagoa facultativa. O sistema mencionado pode reduzir para cerca de $1 / 3$ a área requerida pelo sistema tradicional de lagoas facultativas, entretanto a existência de uma etapa anaeróbia pode ocasionar a liberação de gás sulfídrico, responsável pelos odores 
fétidos, provocando mau cheiro. É um sistema simples que não requer mão-de-obra especializada sendo está de simples execução (SANTOS, 2007).

Santos (2007) conceitua o sistema de lodos ativados como sendo o tratamento em que se faz retornar ao tanque de aeração parte da matéria orgânica que será decantada no decantador secundário, fazendo assim com que haja também uma circulação das bactérias aumentando a concentração destas no tanque de aeração. As unidades essenciais nesse sistema são o tanque de aeração, tanque de decantação, elevatória de recirculação de lodo. A concentração de sólidos em suspensão no tanque de aeração é mais de 10 vezes superior à de uma lagoa aerada de mistura completa.

Com um baixo tempo de detenção esse sistema requer uma área bem pequena para a implantação, o tempo de detenção é da ordem de 6 a 8h. Com a recirculação, entretanto, os sólidos permanecem por mais tempo, na ordem de 4 a 10 dias. Esse tempo dos sólidos no sistema garante ao lodo ativado a elevada eficiência. Para se economizar em termos de energia para aeração, parte da matéria orgânica é retirada dos esgotos antes do tanque de aeração através do decantador primário.

Devido à alta recirculação dos sólidos com o aumento das bactérias, é necessário a presença de mecanismos de controle para fazer com que o sistema fique em equilíbrio, já que o aumento descontrolado das bactérias ocasionaria uma demanda excessiva por oxigênio, fazendo com que o sistema não tratasse satisfatoriamente os sólidos. Esse sistema de controle pode ser a retirada do lodo biológico que pode ser extraída diretamente do reator o da linha de recirculação. O sistema de lodos ativados ocupa áreas bem inferiores às do sistema de lagoas, no entanto o fluxograma do sistema é bastante complicado exigindo mão de obra especializada para a sua operação, e os gastos com energia elétrica são um pouco superiores aos de lagoas aeradas.

\section{A Legislação Brasileira}

Velasco (2017) revela que, mesmo depois de uma década da Lei de Saneamento Básico, mais de 50\% da população brasileira ainda segue sem tratamento de esgoto. Em 2007, quando a Lei 11.445 foi sancionada pelo então presidente, $42 \%$ da população era atendida por redes de esgoto. Já em 2015, passou para 50,3\%. No Norte do país a situação é ainda mais grave apenas $7,4 \%$ da população é atendida com esgoto. 0 pior estado do país é o Amapá com 3,8\% da população sendo atendida com rede esgoto, respectivamente. Já o melhor estado é São Paulo com $88,4 \%$ da população atendida tem rede de esgoto. Outro estado que destaca é o Distrito Federal com $84,5 \%$.

Nunes (2015) descreve que a lei 11.445 estabelece diretrizes nacionais para o saneamento básico e para a política federal em saneamento básico com vistas na universalização dos seus serviços. A lei valoriza o planejamento no alcance da referida universalização ao estabelecer a obrigatoriedade da elaboração de Planos Municipais de Saneamento Básico (PMSB) por parte dos titulares dos serviços, ou seja, os municípios. Os PMSBs contém o planejamento de ações no longo prazo e seu conteúdo mínimo apresenta, entre outras coisas: o diagnóstico da atual situação dos serviços de saneamento do município; os objetivos e metas de 
curto, médio e longo prazo; os programas e projetos de ações compatíveis com os planos plurianuais; e os mecanismos de avaliação e controle das ações previstas.

Nunes (2015) descreve ainda que a lei tem os objetivos de: garantir o cumprimento das metas dos contratos de saneamento a partir do estabelecimento de padrões e normas para a adequada prestação dos serviços; definir tarifas que assegurem o equilíbrio econômico-financeiro dos contratos e a modicidade tarifária; prevenir e reprimir o abuso do poder econômico, ressalvada a competência dos órgãos integrantes do sistema nacional de defesa da concorrência e; estimular a eficiência e eficácia dos prestadores de serviços, bem como a apropriação social dos ganhos de produtividade. A evolução no quadro de tratamento de esgoto pode ser melhor compreendida no gráfico 1, que mostra um crescimento entre os anos de 2007 a 2015.

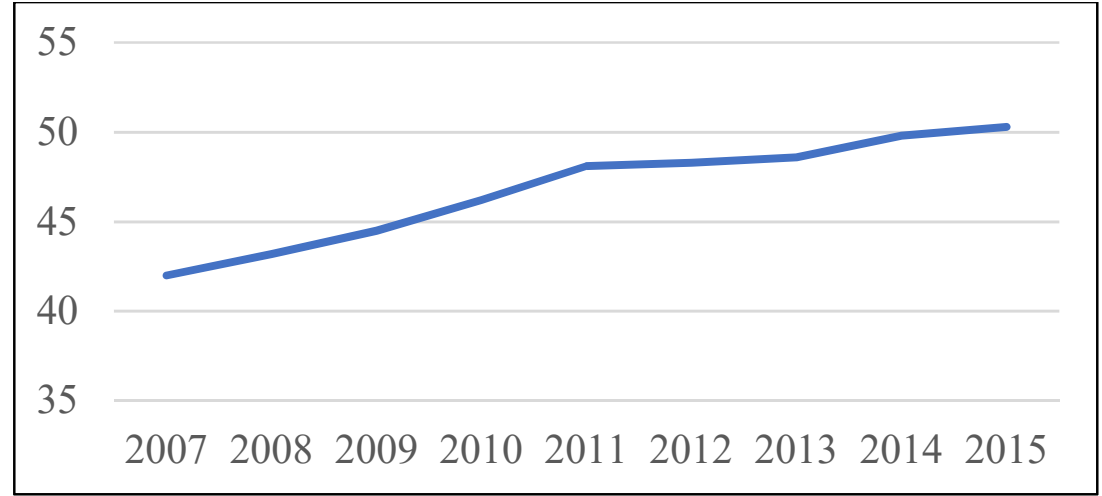

Gráfico 1: Tratamento de Esgoto no Brasil (\%). Fonte: Velasco (2017).

Além da Lei do Saneamento Básico, em 2014 foi criado o Plano Nacional de Saneamento Básico (PNSB), elaborado pela Lei no 11.445/2007, doravante denominado PLANSAB, resulta de um processo planejado e coordenado pelo Ministério das Cidades em três etapas: a formulação do Pacto pelo Saneamento Básico: mais saúde, qualidade de vida e cidadania em 2008; a elaboração, em 2009 e 2010, de extenso estudo denominado Panorama do Saneamento Básico no Brasil; a Consulta Pública, que submeteu a versão preliminar do Plano à sociedade, promovendo sua ampla discussão e posterior consolidação de sua forma final à luz das contribuições acatadas (BRASIL, 2014).

Ainda segundo Brasil (2014) a estrutura do PLANSAB inicia-se com uma apresentação das bases legais e dos princípios norteadores e orientadores. Em seguida, apresenta-se a síntese da análise situacional do saneamento básico no Brasil, composta pelos estudos dos déficits, dos programas e ações federais, dos investimentos realizados pelo Governo Federal e pela avaliação político-institucional do setor. Nas seções seguintes são descritos os três cenários para a política de saneamento básico e mostradas as metas de curto, médio e longo prazo, por macrorregião, para o cenário de referência.

Apresenta-se a projeção das necessidades de investimento, por componente do saneamento básico, para o cumprimento das metas previstas. Posteriormente, são apontadas as macrodiretrizes, estratégias e os programas de governo entendidos como necessários para a materialização efetiva, eficaz e eficiente do Plano. Finalmente, propõe-se a estrutura e os procedimentos visualizados para o monitoramento, avaliação sistemática e revisão do Plano. 
Em Goiás, no ano de 1999, o saneamento ambiental enfrentava um déficit assustador, assim foi iniciado a aplicação de um ousado programa que se estende há anos, com resultados de proporções gigantescas, diretamente responsáveis pelos índices positivos de expectativa de vida da população de nosso Estado.

Os investimentos globais tornaram possíveis pela parceria dos estados de Goiás e do DF, que viabilizam o consórcio, com redução no preço final. O objetivo é garantir o abastecimento de água nas duas unidades da Federação pelos próximos 100 anos, assim o estado de Goiás realiza todos os esforços para não apenas cumprir, mas ir além das metas, dentro do propósito geral de atender as comunidades com água tratada e esgotamento sanitário, providência prioritária para a garantia de saúde preventiva, proteção aos mananciais hídricos e ao meio ambiente e a conquista de uma vida verdadeiramente saudável (PERILLO, 2013).

Em especial na cidade de Itumbiara (GO) a AGR (2017) descreve que a Estação de Tratamento de Esgoto (ETE) do município opera dentro de sua capacidade instalada, atendendo a população da cidade, com eficiência de remoção em sua maioria acima de $80 \%$. Quando leva em consideração a vazão média, DBO de entrada e eficiência de remoção de DBO verifica-se que não há necessidade operacional de se colocar os novos reatores em operação no momento, porém eles foram colocados em carga no final 2017, atendendo à solicitação de outras unidades. Diante desse dado constata-se que a ETE de Itumbiara está concluída e em pleno funcionamento. Verificou-se também que não existe mais o lançamento de esgotos in natura no Rio Paranaíba provenientes do by-pass das elevatórias de esgoto.

\section{CONSIDERAÇÕES FINAIS}

Com a realização desse estudo pode-se observar que há legislação para a políticas de saneamento no Brasil. Porém ainda não uma abrangência significativa no país. Deve-se estar atento que há tratamentos de esgotos disponíveis no mercado que cabe a qualquer tipo de situação e também quando relacionado a custo, porém ainda há pouco trabalho ou assim podemos dizer 'interesse' dos nossos governantes em oferecer um tratamento do esgoto a maioria da população. Conclui-se que o mercado disponibiliza de vários tratamentos tecnológicos para o esgoto e que a cada dia há uma lenta evolução na cobertura desse serviço à população brasileira.

\section{REFERÊNCIAS}

AGR. Agência Goiana de Regulação. Saneamento de Goiás S/A: SANEAGO. Goiânia: AGR, 2017.

BRASIL. Ministério das Cidades. Plano Nacional de Saneamento Básico Mais Saúde com Qualidade de Vida e Cidadania. Brasília: MC, 2014.

BRASIL. Ministério das Cidades. Processos de tratamento de esgotos: guia do profissional em treinamento: nível 1. Brasília: MC, 2008.
DUTRA, J.. Medindo o saneamento: potencialidades e limitações dos bancos de dados brasileiros. Brasília: FGV, 2018.

FLORENCIO, L.; BASTOS, F. R. K. X.; AISSE, M. M.. Tratamento e Utilização de Esgotos Sanitários. Recife: 2006.

FOLGOSI, V.. A Tecnologia disponível e Evolução do Saneamento Básico no Brasil. São Paulo: FGV, 2014.

NUNES, V. R. S.. O setor de saneamento básico no Brasil: desafios e perspectivas. Rio de Janeiro: 2015. 
OLIVEIRA, C. M. R.. Aplicabilidade de sistemas simplificados para estações de tratamento de esgoto de cidades de pequeno porte. Juiz de Fora: 2014.

PERILLO, M.. Investir em Saneamento para uma vida saudável. Goiânia: 2013.

PIMENTA, H. C. D.; TORRES, F. R. M.; RODRIGUES, B. S.; ROCHA JÚNIOR, J. M.. O esgoto: a importância do tratamento e as opções tecnológicas. Santa Maria: UFSM, 2002.

RODRIGUES, C. M.. Rede coletora de esgoto. Rio de Janeiro: IBGE, 2011.
SANTOS, P. R.. Lagoas de estabilização: solução para o tratamento de esgotos domiciliares. Itatiba: 2007.

SCÓTTA, J.. Avaliação e otimização de uma estação de tratamento de esgoto com sistema fossa e filtro de um munícipio da serra gaúcha. Lajeado: 2015.

VELASCO, C.. Saneamento melhora, mas metade dos brasileiros segue sem esgoto no país. São Paulo: 2017.

VIEIRA, S. M. M.. Tratamento de esgotos domésticos por reator anaeróbico de fluxo ascendente e manto de lodo reator UASB. São Paulo: 1996.

A CBPC - Companhia Brasileira de Produção Científica (CNPJ: 11.221.422/0001-03) detém os direitos materiais desta publicação. Os direitos referem-se à publicação do trabalho em qualquer parte do mundo, incluindo os direitos às renovações, expansões e disseminações da contribuição, bem como outros direitos subsidiários. Todos os trabalhos publicados eletronicamente poderão posteriormente ser publicados em coletâneas impressas sob coordenação da Sustenere Publishing, da Companhia Brasileira de Produção Científica e seus parceiros autorizados. Os (as) autores (as) preservam os direitos autorais, mas não têm permissão para a publicação da contribuição em outro meio, impresso ou digital, em português ou em tradução. 